BMJ Open Diabetes

Research \& Care

\section{High prevalence of cardiovascular risk factors and insulin resistance 6 years after hyperglycemia first detected in pregnancy in Cape Town, South Africa}

To cite: Chivese T, Norris SA, Levitt NS. High prevalence of cardiovascular risk factors and insulin resistance 6 years after hyperglycemia first detected in pregnancy in Cape Town, South Africa. BMJ Open Diab Res Care 2019;7:e000740. doi:10.1136/ bmjdrc-2019-000740

\section{- Additional material is} published online only. To view please visit the journal online (http://dx.doi.org/10.1136/ bmjdrc-2019-000740).

Received 11 July 2019 Revised 24 September 2019 Accepted 23 October 2019
Check for updates

(c) Author(s) (or their employer(s)) 2019. Re-use permitted under CC BY-NC. No commercial re-use. See rights and permissions. Published by BMJ.

For numbered affiliations see end of article.

Correspondence to Dr Tawanda Chivese; tchivese@gmail.com

\section{ABSTRACT}

Objective To investigate the prevalence and associated cardiovascular risk factors 6 years after hyperglycemia first detected in pregnancy (HFDP) in Cape Town, South Africa. Research design and methods Data were collected during the index pregnancy from all women diagnosed with HFDP at a major referral hospital in Cape Town. Participants were evaluated 6 years later using a cross-sectional study. At follow-up participants had a $75 \mathrm{~g}$ oral glucose tolerance test, fasting lipogram, blood pressure and anthropometric measurements, and a fieldworker administered the questionnaire. We used the Adult Treatment Panel III criteria for the diagnosis of metabolic syndrome and individual risk factors. Insulin resistance was assessed using the homeostatic model of insulin resistance.

Results At follow-up 220 women were reviewed. Their mean age at follow-up was 37.2 (SD 6.0) years. The prevalence of cardiovascular disease (CVD) risk factors was $60.9 \%$ (95\% Cl 54.3 to 67.2 ) for metabolic syndrome, $75 \%$ (95\% Cl 65.9 to 82.3) for insulin resistance, $62.3 \%$ (95\% Cl 55.6 to 68.5$)$ for dysglycemia, $41.4 \%(95 \% \mathrm{Cl} 35.0$ to 48.0) for raised blood pressure, and $74.6 \%$ (95\% Cl 683 to 79.9) for dyslipidemia. Women with diabetes in pregnancy compared with those with gestational diabetes during the index pregnancy had a higher prevalence of metabolic syndrome $(74.3 \%$ vs $54.7 \%, p=0.010)$ and dysglycemia (88.6\% vs $50.0 \%, \mathrm{p}<0.001)$ at follow-up. Lower school education attainment, having a subsequent pregnancy, waist circumference at follow-up, and fasting blood glucose at HFDP diagnosis were associated with metabolic syndrome. Conclusion We found a high prevalence of CVD risk factors in South African women within 6 years of HFDP, which highlights the need to develop and evaluate interventions optimizing the cardiometabolic health of this vulnerable group. The main limitations of our research are the lack of a comparative group of women without HFDP and that we did not assess for CVD risk factors before HFDP.

\section{BACKGROUND}

Non-communicable diseases (NCDs) are the leading causes of illness and death worldwide. They accounted for $71 \%$ of overall mortality, in 2016, while cardiovascular diseases (CVD) and diabetes were responsible for almost half $(47.6 \%)$ of the NCD burden. ${ }^{1}$ The majority of premature deaths from NCDs (85\%)

\section{Significance of this study}

What is already known about this subject?

- Women with a history of hyperglycemia first detected in pregnancy (HFDP), which includes gestational diabetes, may have a higher risk for cardiovascular disease (CVD), although to our knowledge there are no data from Africa.

What are the new findings?

- In this study, we found a high prevalence of CVD risk factors 6 years after HFDP in women with a mean age of 37 years in Cape Town, South Africa.

How might these results change the focus of research or clinical practice?

- Given their relatively young age, there is a need for research which investigates innovative interventions to encourage women to change their lifestyles after HFDP, to reduce the risk of CVD.

- These women may require frequent screening for CVD risk factors after pregnancy.

occur in low-income to middle-income countries, ${ }^{1}$ where health systems are struggling to cope with the concurrent problems of infectious diseases and emerging NCDs. In South Africa, the rapidly increasing prevalence of NCDs contributes to the multiple burden of disease, comprising tuberculosis and HIV, ongoing malnutrition, and high maternal and child mortality. ${ }^{23}$ Diabetes and CVD have been the second and third leading causes of death in the country since $2014,{ }^{4}$ highlighting the need to prioritize their prevention. One prevention strategy could be through identification of high-risk populations and offering tailored interventions.

Recent South African epidemiologic surveys show that at least a quarter of pregnant women (26\%) have hyperglycemia first detected in pregnancy (HFDP) ${ }^{5}$ while almost $10 \%$ have gestational diabetes mellitus (GDM) ${ }^{6}$ This may increase their risk for 
early CVD. However, as the risk factor-based screening currently being used in South Africa is suboptimal, a significant proportion of pregnant women are not screened for HFDP. ${ }^{5}$ Until recently, GDM was defined as HFDP with a postpartum return to normalcy in many guidelines. Further, the criteria used for the diagnosis of GDM have varied widely in different countries. However, the WHO 2013 guidelines, ${ }^{8}$ which were largely based on the results of the Hyperglycemia and Adverse Pregnancy Outcomes Study, ${ }^{9}$ and the recommendations of the International Association of Diabetes and Pregnancy Study Groups ${ }^{10}$ have been adopted by many regional and national bodies. These WHO guidelines include the adoption of lower fasting glucose cut-offs and the distinction between GDM and diabetes in pregnancy (DIP), where blood glucose concentrations are diagnostic of type 2 diabetes mellitus.

Meta-analyses have shown that women with a history of GDM (although these studies also included women with DIP, according to the WHO 2013 criteria) have double the risk for overall CVD ${ }^{11} 12$ and coronary artery disease in the long term ${ }^{12}$ and four times the risk for metabolic syndrome ${ }^{13}$ compared with women with normoglycemic pregnancies. ${ }^{13}$ There may be population differences in the association between GDM and metabolic syndrome, as Asian studies did not show the association seen with other populations. Although metabolic syndrome's utility as a clinical entity is debatable, it represents a constellation of risk factors for CVD, with possible common pathophysiology and common environmental risk factors. Insulin resistance, thought to be central in the development of metabolic syndrome,$^{14}$ is also associated with beta-cell deterioration during the immediate post-HFDP period $^{15}$ and consequent progression to type 2 diabetes. ${ }^{16}$

To the best of our knowledge, there are no published studies on the intermediate and long-term burden of CVD in African women post-HFDP, despite the increasing understanding of the critical role women of childbearing age play in the possible intergenerational transmission of and prevention of CVD risk. The aim of this study was to describe the prevalent metabolic syndrome, insulin resistance and individual CVD risk factors (raised blood pressure, dysglycemia, dyslipidemia, raised waist circumference, and overweight and obesity) and their risk factors in women 6 years post-HFDP in Cape Town, South Africa. We also compared the prevalence of metabolic syndrome and individual CVD risk factors between GDM and DIP groups, after reclassifying HFDP, post hoc, using modified WHO 2013 criteria.

\section{METHODS}

All women diagnosed and treated for GDM at a major tertiary referral hospital in Cape Town, South Africa, between 1 August 2010 and 30 September 2011, were eligible for a cross-sectional follow-up study 6 years later. At the time of the pregnancy, GDM was defined as any glucose intolerance first detected in pregnancy according to the
2008 National Institute for Health and Care Excellence guidelines (fasting glucose $>5.6 \mathrm{mmol} / \mathrm{L}$ and oral glucose tolerance test (OGTT) 2-hour glucose $\geq 7.8 \mathrm{mmol} / \mathrm{L}$ ). ${ }^{17}$ We retrospectively classified these women using modified WHO 2013 criteria as HFDP, since the criteria used at the time of the pregnancy included women with GDM and those with DIP, and then grouped the participants into GDM (fasting glucose 5.6-6.9 mmol/L and OGTT 2-hour glucose $7.8-11.0 \mathrm{mmol} / \mathrm{L}$ ) and DIP (fasting glucose $\geq 7.0 \mathrm{mmol} / \mathrm{L}$ and OGTT 2-hour glucose $\geq 11.1 \mathrm{mmol} / \mathrm{L}$ ). Between 1 May 2016 and 30 March 2017, the women were invited for follow-up assessment via telephone, postal mail and home visits. Women with known type 1 or type 2 diabetes were excluded during the pregnancy and pregnant women were excluded from the follow-up study.

\section{Study procedures}

Pregnancy-related data were collected during the index pregnancy, as part of routine clinical care, but women, as part of this study, were not assessed for the following CVD risk factors as they are affected by the pregnancy: central obesity, raised blood pressure and dyslipidemia. At follow-up, participants were invited to come for assessment at the research unit.

Trained fieldworkers administered a questionnaire (adapted from the WHO STEPWise survey questionnaire ${ }^{18}$ ) to collect sociodemographic, breastfeeding and potential risk factor information. The following sections of the core WHO STEPWise questionnaire were used: history of chronic illnesses, physical measurements, and alcohol and tobacco use, in addition to questions on reproductive health. Physical activity was assessed using the modified Global Physical Activity Questionnaire (GPAQ). Average breastfeeding length was calculated as the total months a participant breast fed divided by the number of children she breast fed.

The fieldworkers carried out anthropometric measurements (height, weight, waist and hip circumference) using standard methods. ${ }^{18}$ Each measurement was repeated three times, at least $5 \mathrm{~min}$ apart, and the average was calculated. Height was measured to the nearest $0.1 \mathrm{~cm}$ using a wall-mounted stadiometer. Weight was measured to the nearest $0.1 \mathrm{~kg}$, with the participant putting on light clothing, without shoes, on a bathroom scale placed on a hard flat floor. Waist circumference was measured to the nearest $0.1 \mathrm{~cm}$ using a flexible tape, with the participant having one layer of clothing, at the midpoint between the lower costal margin and the level of the superior iliac crests. Hip circumference was measured to the nearest $0.1 \mathrm{~cm}$ at the widest part of the hip, with a flexible tape held horizontally. Each participant had three blood pressure measurements $5 \mathrm{~min}$ apart while seated comfortably, using an Omron automated blood pressure monitor (Omron 711; Omron Healthcare, Hamburg, Germany). The average of the last two readings was used in analyses.

Each participant underwent a $75 \mathrm{~g}$ OGTT (unless already diagnosed with diabetes) after fasting for 8-10 hours. Fasting blood was drawn for glucose, insulin 
and lipids. In addition, blood was drawn at 2 hours for glucose. Participants on treatment for high blood pressure, raised blood lipids and diabetes were not required to give samples or take measurements for the respective conditions. The samples were kept on ice until centrifugation within 4 hours of collection and the aliquots stored at $-80^{\circ} \mathrm{C}$ until biochemical analysis.

\section{Outcomes}

The outcomes were metabolic syndrome (having $\geq 3$ CVD risk factors) and individual CVD risk factors (dysglycemia, raised blood pressure, dyslipidemia and central obesity), defined according to a modified National Cholesterol Education Program Adult Treatment Panel III. ${ }^{19}$ Raised blood pressure was defined as either diastolic blood pressure above $85 \mathrm{~mm} \mathrm{Hg}$ and/or systolic blood pressure above $130 \mathrm{~mm} \mathrm{Hg}$. Dyslipidemia was defined as either triglycerides $\geq 1.7 \mathrm{mmol} / \mathrm{L}$ and/or high-density lipoprotein cholesterol $\leq 1.30 \mathrm{mmol} / \mathrm{L}$. Dysglycemia was defined as fasting plasma glucose $\geq 5.6 \mathrm{mmol} / \mathrm{L}$. Body mass index (BMI) was grouped according to WHO criteria for underweight $\left(<18.5 \mathrm{~kg} / \mathrm{m}^{2}\right)$, normal weight $\left(18.5-24.9 \mathrm{~kg} / \mathrm{m}^{2}\right)$, overweight $\left(25-29.9 \mathrm{~kg} / \mathrm{m}^{2}\right)$, obese $\left(30-39.9 \mathrm{~kg} / \mathrm{m}^{2}\right)$ and morbidly obese $\left(>40 \mathrm{~kg} / \mathrm{m}^{2}\right)$, while a waist circumference cut-off of $\geq 88 \mathrm{~cm}$ was used for central obesity. ${ }^{20} \mathrm{We}$ assessed insulin resistance using the homeostatic model assessment of insulin resistance using a cut-off of 1.95, as used in a previous study in obese South African women. ${ }^{21}$ Participants with known diabetes at the time of follow-up were excluded from insulin resistance assessment.

\section{Biochemistry and laboratory analyses}

Plasma glucose was measured using the hexokinase method on a Randox RX Daytona Chemistry Analyzer. Enzymatic colorimetric assays were used to measure triglycerides, total cholesterol and high-density lipoprotein cholesterol using the Roche Modular Auto Analyzer, while low-density lipoprotein cholesterol was calculated using direct methods. Coefficients of variation calculated from running 40 separate samples in duplicate were $3.0 \%$ for glucose, $3.1 \%$ for cholesterol, $3.1 \%$ for triglycerides and $3.4 \%$ for insulin.

\section{Statistical data analysis}

Stata V.15 statistical software ${ }^{22}$ was used for all analyses, with $\mathrm{p}<0.05$ for significance and 95\% CI reported for estimates, where appropriate. Means and SDs are presented for normally distributed measured data, medians and IQRs for non-normally distributed data, and frequencies and proportions for categorical variables. Comparisons of participants with metabolic syndrome and those without were done using the $\chi^{2}$ test for categorical data and independent groups t-test (normally distributed measured data) or Wilcoxon rank-sum test (for measured data that were not normally distributed). The prevalence of CVD risk factor was calculated as the proportion of participants with the outcome over the total assessed.
To explore factors associated with metabolic syndrome, multiple variable logistic regression was used. Pregnancyrelated variables entered into the logistic regression models were fasting and 2-hour OGTT glucose levels at HFDP diagnosis and type of treatment during HFDP. Variables measured at follow-up included in the logistic regression were socioeconomic characteristics (age, ethnicity, education and employment), anthropometry (waist and hip circumference, BMI), family history of high blood pressure, reproductive health factors (subsequent pregnancy (yes/no) and average breastfeeding length in months), total minutes of physical activity per week from the modified GPAQ, and smoking (current smoker or not). Stopping alcohol due to health reasons and BMI at pregnancy booking were not included in the multiple logistic regression due to missing data.

For each of the following individual CVD risk factors, we explored risk factors using multiple variable logistic regression separately: raised blood pressure, dysglycemia, dyslipidemia and insulin resistance. Bonferroni adjustment was used to compensate for multiple testing by multiplying the individual $\mathrm{p}$ values by the total number of outcomes (four). For insulin resistance, only the 108 participants who had no diabetes at follow-up and had fasting insulin measurements were included.

Logistic regression model diagnostics included linearity assumption testing using the Lowess graph, multicollinearity testing using variance inflation factors (VIF), using a a cut-off of the square of the VIF above 4, model specification testing using the C-statistic linktest (_hatsq), and confirmation of the fit of the model using the Hosmer-Lemeshow goodness-of-fit test. The area under the receiving operating characteristic (ROC) curve and $k$-fold cross-validation $(\mathrm{k}=10)$ were used for model validation. The study is reported according to the Strengthening the Reporting of Observational Studies in Epidemiology $^{23}$ guidelines.

\section{RESULTS}

Two hundred and twenty participants $(44.2 \%)$ were followed up (figure 1). There were no differences in any sociodemographic characteristics during the index HFDP in those followed up compared with the women lost to follow-up. However, compared with participants lost to

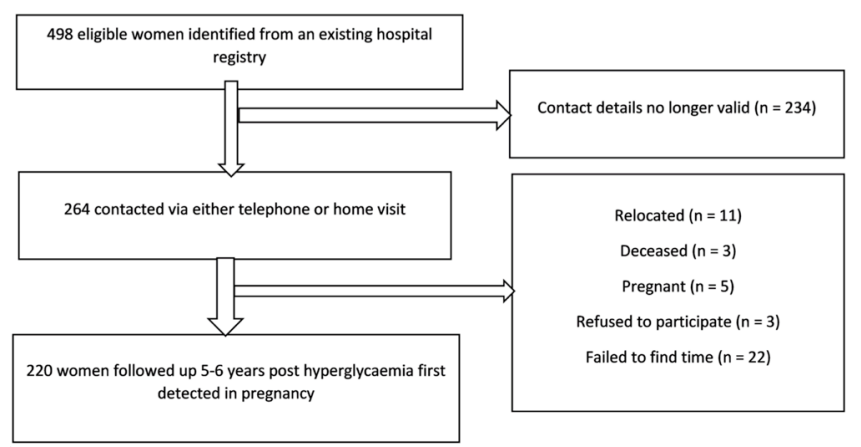

Figure 1 Study flow chart. 
follow-up, participants assessed at follow-up had higher median BMI at booking (34.6 (IQR 28.8-41.4) $\mathrm{kg} / \mathrm{m}^{2}$ vs 32.7 (IQR 27.6-38.4) kg/m² , respectively) but lower median 2-hour OGTT glucose concentrations at HFDP diagnosis (9 (IQR 8.2-10) $\mathrm{mmol} / \mathrm{L}$ vs 12 (IQR 11.2-12.8) $\mathrm{mmol} / \mathrm{L}$, respectively) (online supplementary table 1 ).

Table 1 shows the characteristics of the participants during the pregnancy and at follow-up, as well as a comparison by metabolic syndrome status. When the HFDP was classified retrospectively using modified WHO 2013 criteria, 70 of the 220 participants were classified as DIP, while the remaining 150 women were classified as GDM.

At booking of the index pregnancy, the participants' mean age was 30.8 (SD 5.9) years, and at follow-up 37.2 (SD 6.0) years. The majority $(142,65.4 \%)$ were of mixed ancestry. Participants with metabolic syndrome at follow-up had significantly higher mean BMI and age at booking of the index pregnancy and higher fasting and OGTT 1-hour and 2-hour blood glucose concentrations at diagnosis of HFDP, compared with those without metabolic syndrome (table 1 ).

One hundred and five $(47.7 \%)$ participants had diabetes at follow-up and were not assessed for insulin resistance. Compared with participants without metabolic syndrome, those with metabolic syndrome had a significantly higher BMI and were significantly less likely to have tertiary education (table 1 ). The anthropometric and biochemical characteristics of the participants at follow-up are shown in online supplementary table 2.

\section{Prevalence of CVD risk factors, metabolic syndrome and insulin resistance at follow-up, and comparison between DIP and GDM groups}

The prevalence of metabolic syndrome was $60.9 \%$ (95\% CI 54.3 to 67.2), and the prevalence of the individual CVD risk factors was $75.0 \%$ (95\% CI 65.9 to 82.3 ) for insulin resistance, $90.4 \%$ (95\% CI 85.6 to 93.7) for waist circumference $\geq 88 \mathrm{~cm}, 74.6 \%$ (95\% CI 68.3 to 79.9 ) for dyslipidemia, $62.3 \%$ (95\% CI 55.6 to 68.5 ) for dysglycemia, $47.3 \%$ (95\% CI 40.7 to 53.9 ) for obesity, $21.8 \%$ (95\% CI 16.8 to 27.8 ) for morbid obesity and $41.4 \%$ (95\% CI 35.0 to 48.0 ) for raised blood pressure (figure 2, online supplementary table 3 ). The proportions of participants already diagnosed with CVD risk factors were as follows: $25.0 \%$ for diabetes, $20.0 \%$ for hypertension and $10.9 \%$ for dyslipidemia (table 1). Compared with women with GDM, women with DIP had higher prevalence of both metabolic syndrome $(74.3 \%$ vs $54 \%, \mathrm{p}=0.010)$ and dysglycemia $(88.6 \%$ vs $50 \%, \mathrm{p}<0.001)$, but the proportions with insulin resistance and the remaining CVD risk factors did not differ significantly between the two groups (online supplementary table 3 ).

\section{Factors associated with metabolic syndrome and individual CVD risk factors at follow-up: multiple variable logistic regression}

After multiple variable logistic regression, fasting blood glucose at HFDP diagnosis (OR 1.5, 95\% CI 1.1 to 2.0, $\mathrm{p}=0.006$ ), having secondary and matric education, compared with tertiary education (OR 2.5, 95\% CI 1.3 to 9.4, $\mathrm{p}=0.014$ ), having a subsequent pregnancy (OR 0.4, $95 \%$ CI 0.2 to 0.9 ), and waist circumference (OR 1.1, $95 \%$ CI 1.0 to $1.1, \mathrm{p}<0.001)$ were independently associated with metabolic syndrome (figure 3 ).

Online supplementary tables 4A,B show the multiple variable logistic regression of factors associated with the individual CVD risk factors. Waist circumference was associated with raised blood pressure (OR 1.1, 95\% CI 1.0 to $1.1, \mathrm{p}=0.036$ ), dyslipidemia (OR $1.1,95 \%$ CI 1.0 to 1.1, $\mathrm{p}=0.32$ ) and dysglycemia (OR 1.1, 95\% CI 1.0 to 1.1 , $\mathrm{p}<0.001)$, while hip circumference was associated with dyslipidemia (OR 0.9, 95\% CI 0.9 to $1.0, \mathrm{p}=0.032$ ) and dysglycemia (OR $0.9,95 \%$ CI 0.9 to $1.0, \mathrm{p}=0.044$ ). Being employed was associated with raised blood pressure (OR $0.3,95 \%$ CI 0.2 to $0.7, \mathrm{p}=0.008)$.

\section{Logistic regression diagnostics and validation: metabolic syndrome outcome}

The Lowess graph indicated an acceptable linear relationship. Hip circumference (VIF 4.39) was removed from the initial model as it was collinear with waist circumference (VIF 3.95) and BMI at follow-up (VIF 4.78). The link function was correctly specified $(\mathrm{p}=0.630)$ and the Hosmer-Lemeshow goodness-of-fit test showed that the model fit was acceptable $(\mathrm{p}=0.444)$. A few influential cases were identified by plotting residual against predicted probabilities, although sensitivity analysis showed no differences in model estimates when these cases were omitted. The model validation was reasonable, the area under the ROC curve was 0.907 , and the crossfield validation with $\mathrm{k}=10$ folds showed pseudo- $\mathrm{R}^{2}$ values which ranged from 0.21 to 0.49 .

\section{DISCUSSION}

In this study of women with a mean age of 37 years and a 6-year history of HFDP, there was a high prevalence of metabolic syndrome as well as of the individual components, with very low proportions of the participants being aware of their disease status. When the HFDP was categorized according to criteria that approximated the WHO 2013 HFDP diagnostic criteria, women with DIP had a higher prevalence of both metabolic syndrome and dysglycemia compared with those classified as GDM. A high waist circumference, lower education attainment, having had a subsequent pregnancy at follow-up and fasting blood glucose at HFDP diagnosis were all independently associated with metabolic syndrome at follow-up. An increase in waist circumference was associated with risk of raised blood pressure, dyslipidemia and dysglycemia.

To our knowledge, this is the first to investigate the prevalence of metabolic syndrome, insulin resistance and individual CVD risk factors in African women post-HFDP. As different study designs, heterogeneous definitions of GDM and different lengths of follow-up complicate comparison of our findings with international data, we 
Table 1 Characteristics of participants, by the presence or absence of metabolic syndrome

\begin{tabular}{|c|c|c|c|c|c|}
\hline & & Overall & $\begin{array}{l}\text { Metabolic syndrome } \\
\text { at follow-up }\end{array}$ & $\begin{array}{l}\text { No metabolic } \\
\text { syndrome at } \\
\text { follow-up ( }<3 \text { CVD } \\
\text { risk factors) }\end{array}$ & $P$ value \\
\hline $\mathrm{n}$ & & 220 & 134 & 86 & \\
\hline \multicolumn{6}{|l|}{ Variables measured at baseline } \\
\hline Age (years) & Mean (SD) & $30.8(5.9)$ & $32.0(5.7)$ & $29.0(5.7)$ & $<0.001$ \\
\hline BMl at booking $\left(\mathrm{kg} / \mathrm{m}^{2}\right)$ & Mean (SD) & $34.2(8.2)$ & $36.2(7.3)$ & $32.2(8.5)$ & $<0.001$ \\
\hline \multirow{4}{*}{$\begin{array}{l}\text { BMI categories at booking, } \\
n(\%)\end{array}$} & Normal & $31(14.5)$ & $7(5.2)$ & $24(27.9)$ & \multirow[t]{4}{*}{$<0.001$} \\
\hline & Overweight & $38(17.8)$ & $17(12.7)$ & $21(24.4)$ & \\
\hline & Obese & $96(44.9)$ & $76(56.7)$ & $26(30.2)$ & \\
\hline & Morbidly obese & $49(22.9)$ & $34(25.4)$ & $15(17.4)$ & \\
\hline \multirow[t]{2}{*}{ HFDP type, n (\%) } & DIP & $70(31.8)$ & $18(22.1)$ & $52(38.8)$ & \multirow[t]{2}{*}{0.01} \\
\hline & GDM & $150(68.2)$ & $67(77.9)$ & $82(61.2)$ & \\
\hline $\begin{array}{l}\text { Insulin treatment for HFDP, } \\
\mathrm{n}(\%)\end{array}$ & Yes & $52(23.6)$ & $39(29.1)$ & $13(15.1)$ & 0.017 \\
\hline \multicolumn{6}{|l|}{ OGTT at HFDP diagnosis } \\
\hline $\begin{array}{l}\text { Fasting blood glucose } \\
(\mathrm{mmol} / \mathrm{L})\end{array}$ & Median (IQR) & $5.8(5.1-6.7)$ & $6.1(5.4-7.1)$ & $5.5(4.9-6.3)$ & $<0.001$ \\
\hline $\begin{array}{l}\text { 1-hour blood glucose } \\
\text { (mmol/L) }\end{array}$ & Median (IQR) & $10.4(9.2-11.6)$ & $10.6(9.5-11.9)$ & $10.0(8.7-11.2)$ & 0.006 \\
\hline $\begin{array}{l}\text { Insulin treatment for HFDP, } \\
\mathrm{n}(\%)\end{array}$ & Yes & $52(23.6)$ & $39(29.1)$ & $13(15.1)$ & 0.017 \\
\hline 2-hour glucose (mmol/L) & Median (IQR) & $9.0(8.3-10.5)$ & $9.1(8.4-1.0)$ & $8.8(8.2-9.6)$ & 0.022 \\
\hline \multicolumn{6}{|c|}{ Variables measured at follow-up } \\
\hline Follow-up time (years) & Median (IQR) & $6.1(2.8-11.0)$ & $5.6(1.1-9.5)$ & $6.9(4.8-12.8)$ & 0.002 \\
\hline \multirow[t]{3}{*}{ Education, n (\%) } & Tertiary & $30(13.6)$ & $9(6.7)$ & $21(24.4)$ & \multirow[t]{3}{*}{0.001} \\
\hline & $\begin{array}{l}\text { Secondary and } \\
\text { matric }\end{array}$ & $167(75.9)$ & $109(81.3)$ & $58(67.4)$ & \\
\hline & Primary & $23(10.5)$ & $16(11.9)$ & $7(8.1)$ & \\
\hline Employed, n (\%) & Yes & $108(49.1)$ & $57(42.5)$ & $51(59.3)$ & 0.015 \\
\hline Marital status, $\mathrm{n}(\%)$ & Married & $141(64.1)$ & $86(64.2)$ & $55(64.0)$ & 0.832 \\
\hline \multirow[t]{3}{*}{ Family history, n (\%) } & Diabetes & $169(76.8)$ & $103(76.9)$ & $66(76.7)$ & 0.983 \\
\hline & Hypertension & $156(70.9)$ & $98(73.1)$ & $58(67.4)$ & 0.364 \\
\hline & $\begin{array}{l}\text { Stroke and heart } \\
\text { attack }\end{array}$ & $96(43.6)$ & $59(44.0)$ & $37(43.0)$ & 0.883 \\
\hline $\begin{array}{l}\text { Stopped drinking alcohol for } \\
\text { health reasons, } \mathrm{n}(\%)\end{array}$ & Yes & $14(6.4)$ & $10(7.5)$ & $4(4.7)$ & 0.486 \\
\hline Current smoker, n (\%) & Yes & $64(29.1)$ & $37(27.6)$ & $27(31.4)$ & 0.547 \\
\hline $\begin{array}{l}\text { GPAQ total physical activity } \\
\text { (min) }\end{array}$ & Median (IQR) & $450(110-1405)$ & $420(177.5-1502.5)$ & $375(90-1280)$ & 0.274 \\
\hline $\begin{array}{l}\text { Subsequent pregnancy, } \mathrm{n} \\
\text { (\%) }\end{array}$ & Yes & $58(26.4)$ & $32(23.9)$ & $26(30.2)$ & 0.297 \\
\hline $\begin{array}{l}\text { Average breastfeeding } \\
\text { length (months) }\end{array}$ & Median (IQR) & $6(1-18)$ & $8(1-18)$ & $6(1-12)$ & 0.332 \\
\hline Follow-up BMI (kg/m²) & Mean (SD) & $34.9(8.7)$ & $36.8(8.3)$ & $32.0(8.6)$ & $<0.001$ \\
\hline Weight gain (kg) & Median (IQR) & $2.0(-4.6$ to 9.0$)$ & $1.5(-7.0$ to 9.0$)$ & $3.3(-3.1$ to 7.9$)$ & 0.511 \\
\hline
\end{tabular}




\begin{tabular}{|c|c|c|c|c|c|}
\hline & & Overall & $\begin{array}{l}\text { Metabolic syndrome } \\
\text { at follow-up }\end{array}$ & $\begin{array}{l}\text { No metabolic } \\
\text { syndrome at } \\
\text { follow-up (<3CVD } \\
\text { risk factors) }\end{array}$ & $P$ value \\
\hline \multirow{4}{*}{$\begin{array}{l}\text { Follow-up BMI categories, } \\
\text { n (\%) }\end{array}$} & Normal & $24(10.9)$ & $6(4.5)$ & $18(20.9)$ & \multirow[t]{4}{*}{$<0.001$} \\
\hline & Overweight & $44(20.0)$ & $21(15.7)$ & $23(26.7)$ & \\
\hline & Obese & $104(47.3)$ & $70(52.2)$ & $34(39.5)$ & \\
\hline & Morbidly obese & $48(21.8)$ & $37(27.6)$ & $11(12.8)$ & \\
\hline Waist circumference (cm) & Mean (SD) & $110.5(17.6)$ & $115.6(16.9)$ & $102.3(15.6)$ & $<0.001$ \\
\hline Hip circumference (cm) & Mean (SD) & $117.3(16.1)$ & $119.3(15.7)$ & $113.9(16.4)$ & 0.008 \\
\hline \multirow{3}{*}{$\begin{array}{l}\text { Self-reported comorbidities, } \\
\text { n (\%) }\end{array}$} & Diabetes & $55(25.0)$ & $45(33.6)$ & $10(11.6)$ & $<0.001$ \\
\hline & Hypertension & $44(20.0)$ & $42(31.3)$ & $2(2.3)$ & $<0.001$ \\
\hline & Dyslipidemia & $24(10.9)$ & $22(16.4)$ & $2(2.3)$ & 0.001 \\
\hline
\end{tabular}

BMI, body mass index; CVD, cardiovascular disease; DIP, diabetes in pregnancy; GDM, gestational diabetes mellitus; GPAQ, Global Physical Activity Questionnaire; HFDP, hyperglycemia first detected in pregnancy; OGTT, oral glucose tolerance test.

have attempted to compare our findings with studies that used criteria for GDM similar to ours as well as a similar duration of follow-up. Our prevalence estimates are similar to data from India, where the reported metabolic syndrome prevalence was $55 \%,{ }^{24}$ dysglycemia prevalence was $68 \%{ }^{25}$ and dyslipidemia was $71 \% .^{24}$ On the other hand, our prevalence estimates are much higher than those reported from other countries. In China, the prevalence of metabolic syndrome was $7.5 \%,{ }^{26}$ in Brazil the prevalence of dysglycemia was $39.4 \%,{ }^{27}$ and in Ireland the prevalence of dyslipidemia was $25 \% .{ }^{28}$ We found only a single study that assessed insulin resistance ${ }^{28}$ to date, which reported a prevalence of $33.6 \%$, which is less than half of the prevalence in our study.

We were unable to find studies that compared CVD risk factors at follow-up between women with DIP and those with GDM. Given that the DIP group may include undiagnosed type 2 diabetes cases, this group's higher prevalence of dysglycemia compared with that in the GDM group is expected. The former's higher metabolic syndrome prevalence could be partly explained by the higher proportion of women with dysglycemia as well as diabetes-associated dyslipidemia. Thus, early intervention and screening for CVD risk factors for women with DIP are warranted.

Our study has several limitations. A major limitation was the lack of a control group. Despite this, we were able to use prevalence estimates based on the same criteria for our outcomes of interest in women of childbearing age from population surveys in Cape Town. In these studies, the prevalence of metabolic syndrome ranged from $9.9 \%{ }^{21}$ to $43 \%,{ }^{29}$ the prevalence of raised blood pressure was $19.9 \%,{ }^{21}$ the prevalence of dysglycemia was $2.2 \%,{ }^{30}$ $17.9 \%{ }^{31}$ and $32.6 \%,{ }^{32}$ the prevalence of dyslipidemia was $46 \%$, and the prevalence of insulin resistance in obese women was $38 \% .^{33}$ Thus, our findings suggest higher prevalences of CVD risk factors in our study population

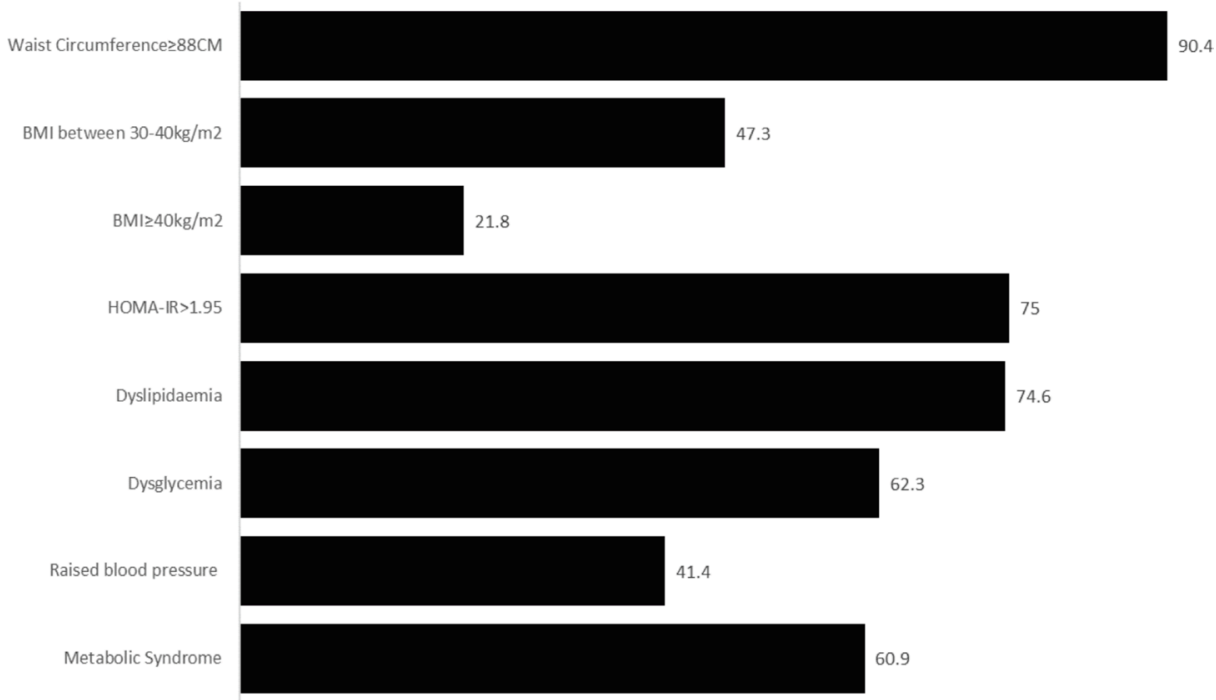

Figure 2 Prevalence of cardiovascular disease risk factors and insulin resistance 6 years after hyperglycemia first detected in pregnancy. BMI, body mass index; HOMA-IR, homeostatic model assessment of insulin resistance. 


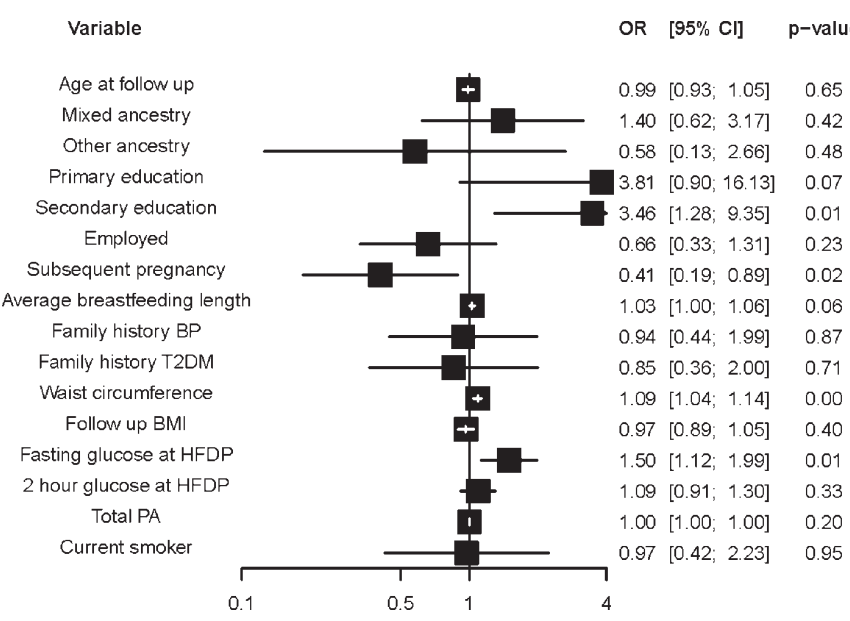

Figure 3 Multiple variable logistic regression for factors associated with metabolic syndrome. Model statistics (observations: 218 , p value: 0.000 , pseudo- $R^{2}: 0.25$ ). BP, blood pressure; BMI, body mass index; HFDP, hyperglycemia first detected in pregnancy; PA, physical activity; T2DM, type 2 diabetes mellitus.

when compared with population-based survey data of women of childbearing age in Cape Town. Interventions to reduce risk of CVD risk factors and consequent CVD should be considered. This has the potential to improve more than the mother's health; it may also reduce the risk of hyperglycemia in future pregnancies and subsequently reduce the potential for intergenerational transmission of CVD risk through fetal programming. ${ }^{34}$

The first intervention could be integrating CVD risk factor screening with the recommended postpartum screening for diabetes. Currently, the recommended 6-week postpartum screening for diabetes has a poor uptake, in keeping with international trends. In our setting, innovative solutions to the various health system and sociodemographic barriers may be required to improve uptake. ${ }^{35}$ The very low number of women who were aware that they had CVD risk factors and on treatment is a cause for concern. Combining the postpartum care of the mother with that of the baby may offer a window to both screen for CVD risk factors and provide an opportunity to engage with the mother to promote change in her modifiable CVD risk factors. This postpartum review may need to be extended to include obese women, as our data showed that high waist circumference was associated with CVD risk factors at follow-up. However, this will have health system implications because of the high prevalence of obesity in South African women of childbearing age. ${ }^{36}$ The high prevalence of obesity has been attributed to changes in diet and physical activity patterns among urban-dwelling South African women. ${ }^{36}$ Lifestyle change should therefore be part of a holistic package to prevent CVD risk in these women while at the same time reducing the consequent cardiometabolic disease risk in future offspring.

A further limitation of our study is that we were only able to assess $44 \%$ of women at follow-up, due to the population being highly mobile. The rate of follow-up is comparable with studies from other low-income to middle-income countries. ${ }^{37}{ }^{38}$ As we followed up fewer women with DIP, we may have underestimated the prevalence of both metabolic syndrome and dysglycemia. On the other hand, the women who we were able to follow up had a higher BMI by 2 units compared with those we were not able to follow-up, thus overestimating the prevalences of the CVD risk factors. Finally, as we did not assess the presence of the CVD risk factors during the index pregnancy, it is difficult to properly estimate the effect of HFDP on the risk of metabolic syndrome and its components.

\section{CONCLUSION}

Given the considerable and growing burden of diabetes and CVD in South Africa, the high prevalence of CVD risk factors found in relatively young African women within 6 years of a previous HFDP highlights the need to develop and evaluate interventions optimizing the cardiometabolic health of this group.

\section{Author affiliations}

${ }^{1}$ Chronic Disease Initiative for Africa, Faculty of Medicine and Health Sciences, University of Cape Town, Cape Town, Western Cape, South Africa

${ }^{2}$ SAMRC/Wits Developmental Pathways for Health Research Unit, Department of Paediatrics, University of the Witwatersrand, Parktown, Gauteng, South Africa

${ }^{3}$ Population Medicine, College of Medicine, Qatar University, Doha, Qatar

${ }^{4}$ School of Human Development and Health, and NIHR Southampton Biomedical Research Centre, University of Southampton, Southampton, UK

Acknowledgements We thank Ms Chantal Stuart (administration and logistics) and Ms Siphokazi Khonkwane (fieldwork) at the Chronic Disease Initiative for Africa for their support during data collection at follow-up. We acknowledge Dr Hetta van Zyl for collecting pregnancy-related data from participants and Professors Krisela Steyn and Christina Zarowsky for help during the conception of the research.

Contributors Conceptualization: TC, SAN, NSL. Data curation: TC. Formal analysis: TC, SAN, NSL. Funding acquisition: SAN, NSL. Investigation: TC. Methodology: TC, SAN, NSL. Project administration: TC. Resources: SAN, NSL. Software: TC. Supervision: SAN, NSL. Validation: TC. Writing of original draft: TC. Review and editing: TC, SAN, NSL.

Funding This research was funded by the Chronic Disease Initiative for Africa. We acknowledge funding from the International Development Research Centre (IDRC) (fund number: 411592) for TC (under the IINDIAGO project).

Competing interests None declared.

Patient consent for publication Not required.

Ethics approval The study was carried out according to the principles of the Helsinki Declaration. The study was approved by the Human Research Ethics Committees of the University of Cape Town (Ref: 656/2015). Informed consent was obtained from all participants. Participants who were found to have either hypertension or diabetes were referred for treatment.

Provenance and peer review Not commissioned; externally peer reviewed.

Data availability statement All data relevant to the study are included in the article or uploaded as supplementary information.

Open access This is an open access article distributed in accordance with the Creative Commons Attribution Non Commercial (CC BY-NC 4.0) license, which permits others to distribute, remix, adapt, build upon this work non-commercially, and license their derivative works on different terms, provided the original work is properly cited, appropriate credit is given, any changes made indicated, and the use is non-commercial. See: http://creativecommons.org/licenses/by-nc/4.0/.

Tawanda Chivese http://orcid.org/0000-0001-6621-6144 


\section{REFERENCES}

1. World Health Organization. Noncommunicable diseases 2016, 2018. Available: https://www.who.int/en/news-room/fact-sheets/detail/ noncommunicable-diseases [Accessed 27 Jan 2019].

2. Kabudula CW, Houle B, Collinson MA, et al. Progression of the epidemiological transition in a rural South African setting: findings from population surveillance in Agincourt, 1993-2013. BMC Public Health 2017;17:424.

3. Mayosi BM, Benatar SR. Health and health care in South Africa - 20 years after Mandela. $N$ Engl J Med Overseas Ed 2014;371:1344-53.

4. Statistics South A. P0309.3 - Mortality and causes of death in South Africa: Findings from death notification, 20162018.

5. Adam S, Rheeder P. Screening for gestational diabetes mellitus in a South African population: prevalence, comparison of diagnostic criteria and the role of risk factors. S Afr Med J 2017;107:523-7.

6. Macaulay S, Ngobeni M, Dunger DB, et al. The prevalence of gestational diabetes mellitus amongst black South African women is a public health concern. Diabetes Res Clin Pract 2018;139:278-87.

7. Coetzee A, Mason D, Hall DR, et al. Prevalence and predictive factors of early postpartum diabetes among women with gestational diabetes in a single-center cohort. Int J Gynecol Obstet 2018;142:54-60.

8. World Health Organization. Diagnostic criteria and classification of hyperglycaemia first detected in pregnancy 2013.

9. Metzger BE, Lowe LP, Dyer AR, et al. Hyperglycemia and adverse pregnancy outcomes. N Engl J Med 2008;358:1991-2002.

10. Metzger BE, Gabbe SG, Persson B, et al. International association of diabetes and pregnancy study groups recommendations on the diagnosis and classification of hyperglycemia in pregnancy. Diabetes Care 2010;33:676-82

11. Kramer CK, Campbell S, Retnakaran R. Gestational diabetes and the risk of cardiovascular disease in women: a systematic review and meta-analysis. Diabetologia 2019;62:905-14.

12. Li J, Song C, Li C, et al. Increased risk of cardiovascular disease in women with prior gestational diabetes: a systematic review and meta-analysis. Diabetes Res Clin Pract 2018;140:324-38.

13. $\mathrm{Xu} \mathrm{Y,} \mathrm{Shen} \mathrm{S,} \mathrm{Sun} \mathrm{L,} \mathrm{et} \mathrm{al.} \mathrm{Metabolic} \mathrm{syndrome} \mathrm{risk} \mathrm{after} \mathrm{gestational}$ diabetes: a systematic review and meta-analysis. PLoS One 2014;9:e87863.

14. Stern MP. Diabetes and cardiovascular disease. The "common soil" hypothesis. Diabetes 1995;44:369-74.

15. Retnakaran R, Qi Y, Ye C, et al. Hepatic insulin resistance is an early determinant of declining -cell function in the first year postpartum after glucose intolerance in pregnancy. Diabetes Care 2011;34:2431-4.

16. Xiang $\mathrm{AH}$, Kjos SL, Takayanagi $\mathrm{M}$, et al. Detailed physiological characterization of the development of type 2 diabetes in Hispanic women with prior gestational diabetes mellitus. Diabetes 2010;59:2625-30.

17. Guidelines Development Group. Management of diabetes from preconception to the postnatal period: summary of NICE guidance. BMJ 2008;336:714-7.

18. World Health Organization. Who steps surveillance manual: the who stepwise approach to chronic disease risk factor surveillance 2005.

19. Expert Panel on Detection, Evaluation, and Treatment of High Blood Cholesterol in Adults. Executive summary of the third report of the National cholesterol education program (NCEP) expert panel on detection, evaluation, and treatment of high blood cholesterol in adults (adult treatment panel III). JAMA 2001;285:2486-97.

20. World Health Organization. Waist circumference and waist-hip ratio report of a who expert consultation, Geneva, 8-11 December 2008, 2008. Available: https://apps.who.int/iris/bitstream/handle/10665/ 44583/9789241501491_eng.pdf?ua=1

21. Jennings CL, Lambert EV, Collins $M$, et al. The atypical presentation of the metabolic syndrome components in black African women: the relationship with insulin resistance and the influence of regional adipose tissue distribution. Metabolism 2009:58:149-57.

22. Stata Crop. College Station (TX). Stata press, 2016.

23. von Elm E, Altman DG, Egger $\mathrm{M}$, et al. The strengthening the reporting of observational studies in epidemiology (STROBE) statement: guidelines for reporting observational studies. PLoS Med 2007;4:e296.

24. Kale SD, Yajnik CS, Kulkarni SR, et al. High risk of diabetes and metabolic syndrome in Indian women with gestational diabetes mellitus. Diabet Med 2004;21:1257-8.

25. Krishnaveni GV, Hill JC, Veena SR, et al. Gestational diabetes and the incidence of diabetes in the 5 years following the index pregnancy in South Indian women. Diabetes Res Clin Pract 2007;78:398-404.

26. Tam WH, Yang XL, Chan JCN, et al. Progression to impaired glucose regulation, diabetes and metabolic syndrome in Chinese women with a past history of gestational diabetes. Diabetes Metab Res Rev 2007;23:485-9.

27. Rivero K, Portal VL, Vieira M, et al. Prevalence of the impaired glucose metabolism and its association with risk factors for coronary artery disease in women with gestational diabetes. Diabetes Res Clin Pract 2008;79:433-7.

28. Noctor E, Crowe C, Carmody LA, et al. ATLANTIC-DIP: prevalence of metabolic syndrome and insulin resistance in women with previous gestational diabetes mellitus by international association of diabetes in pregnancy study groups criteria. Acta Diabetol 2015;52:153-60.

29. Peer N, Lombard C, Steyn K, et al. High prevalence of metabolic syndrome in the black population of Cape town: the cardiovascular risk in black South Africans (CRIBSA) study. Eur J Prev Cardiol 2015;22:1036-42.

30. Catapano AL, Graham I, De Backer G, et al. 2016 ESC/EAS Guidelines for the Management of Dyslipidaemias: The Task Force for the Management of Dyslipidaemias of the European Society of Cardiology (ESC) and European Atherosclerosis Society (EAS) Developed with the special contribution of the European Assocciation for Cardiovascular Prevention \& Rehabilitation (EACPR). Atherosclerosis 2016;253:281-344.

31. Peer N, Steyn K, Lombard C, et al. Rising diabetes prevalence among urban-dwelling black South Africans. PLoS One 2012;7:e43336.

32. Erasmus RT, Soita DJ, Hassan MS, et al. High prevalence of diabetes mellitus and metabolic syndrome in a South African coloured population: baseline data of a study in Bellville, Cape town. S Afr Med J 2012;102:841-4.

33. Jennings CL, Lambert EV, Collins M, et al. Determinants of insulinresistant phenotypes in normal-weight and obese black African women. Obesity 2008;16:1602-9.

34. Nehring I, Chmitorz A, Reulen H, et al. Gestational diabetes predicts the risk of childhood overweight and abdominal circumference independent of maternal obesity. Diabet Med 2013;30:1449-56.

35. Venkataraman H, Sattar N, Saravanan P. Postnatal testing following gestational diabetes: time to replace the oral glucose tolerance test? Lancet Diabetes Endocrinol 2015;3:754-6.

36. Gradidge PJ-L, Crowther NJ. Review: metabolic syndrome in black South African women. Ethn Dis 2017;27:189-200.

37. Gupta Y, Kapoor D, Desai A, et al. Conversion of gestationa diabetes mellitus to future Type 2 diabetes mellitus and the predictive value of $\mathrm{HbA}_{1 \mathrm{c}}$ in an Indian cohort. Diabet Med 2017:34:37-43

38. Liu Z-Y, Zhao J-J, Gao L-L, et al. Glucose screening within six months postpartum among Chinese mothers with a history of gestational diabetes mellitus: a prospective cohort study. BMC Pregnancy Childbirth 2019;19:134.

39. Helsinki WEU. Do. World Medical association Declaration of Helsinki. Fortaleza, Brazil, 2013. 